\title{
Measurement Instrument and Indicators of Subjective Well-Being: A Review Paper
}

\author{
Nurul Hafizah Azizan, Zamalia Mahmud, Adzhar Rambli \\ Faculty of Computer and Mathematical Science, \\ Universiti Teknologi MARA, Malaysia \\ hafizahaz@kelantan.uitm.edu.my, zamalia@tmsk.uitm.edu.my, adzhar_rambli@tmsk.uitm.edu.my
}

\begin{abstract}
Subjective well-being is focusing on happiness and life satisfaction of the people. This review is carried out to examine the contributing factors of people's happiness and life satisfaction and also to determine the measurement instrument used in conducting a survey. A total of 60 articles obtained from academic search engines and online databases which are Google Scholar, ScienceDirect and Scopus have been chosen to be reviewed within a period from September 2017 until January 2018. Only 33 articles indexed in Scopus and ISI are eligible for final review.
\end{abstract}

Keywords: Subjective well-being; happiness; life satisfaction

eISSN 2514-7528 @ 2018. The Authors. Published for AMER ABRA cE-Bs by e-International Publishing House, Ltd., UK. This is an open-access article under the CC BY-NC-ND license (http://creativecommons.org/licenses/bync-nd/4.0/). Peer-review under responsibility of AMER (Association of Malaysian Environment-Behaviour Researchers), ABRA (Association of Behavioural Researchers on Asians) and CE-Bs (Centre for EnvironmentBehaviour Studies), Faculty of Architecture, Planning \& Surveying, Universiti Teknologi MARA, Malaysia.

https://doi.org/10.21834/jabs.v3i11.322 


\subsection{Introduction}

Society's well-being has become a global issue since it has received considerable attention in many countries all over the world. Well-being issues are crucial to being taken lightly. This is because by addressing the issues that relate to the well-being of individuals and group of people will assist the government in implementing relevant and practical public policies to the society. Currently, there is a growing research interest in subjective well-being which deals with latent constructs such as life satisfaction and happiness as it provides useful information about the respondents' feelings and experiences. Subjective well-being which is denoted as SWB was first introduced by Diener (1984) which attempts to understand people's evaluation of their quality of life, and mostly related to happiness and life satisfaction. SWB is a part of a quality of life where it measures how people feel about their lives and whether a person likes his/her life being experienced. It also concerned with individuals' subjective experience of their lives with people's conscious experiences - in terms of hedonic feelings or cognitive satisfactions (Diener \& Suh, 1997). As stated by Diener, Suh, and Oishi (1997), those who are satisfied with their life with frequent positive affect and infrequent negative affect are the people with high SWB, while the people with low SWB are those who feel dissatisfied with their life, experience little joy with negative emotion such as anger and anxiety.

According to Diener et al. (1997), SWB is an evaluation judgment about specific aspects of his or life. Diener, Oishi, and Lucas (2012) also highlighted that the term of "subjective well-being" refers to a person's cognitive and affective evaluations of his or her life; when a person gives conscious evaluation judgments about his or her satisfaction with life as a whole. As claimed by Diener \& Chan (2011) good subjective well-being can lead to better health and longevity of the people. It implies that those with higher SWB are more productive and could contribute to the success of the organization, societies and also to the country. In addition, Diener, Oishi, and Lucas (2015) also pointed that all government policies such as income security through pensions, unemployment insurance, and compensation for the disabled could lead to SWB of the people. Therefore, a survey on SWB is significant to be carried out as it will assist the government especially policymakers in developing relevant public policies which meet the basic needs of the societies. This review is carried out to address the specific questions as follows:

(1) What is the measurement instrument used in conducting a survey on subjective wellbeing?

(2) What are the factors significantly influence the subjective well-being of the respondents? In order to obtain this information, several possible articles published in a number of journals will be reviewed.

\subsection{Methodology}

Particularly, a systematic review was undertaken to see the trend occur in previous studies related to the subjective well-being survey. It has been conducted to answer the specific research questions highlighted earlier. It is done based on a process of analysing and synthesising previous researches. The five sequential steps as suggested by 
Step 1: Framing questions for a review

The problems to be addressed by the review should be specified in the form of clear, unambiguous and structured questions before beginning the review work. Once the review questions have been set, modifications to the protocol should be allowed only if alternative ways of defining the populations. interventions, outcomes or study designs become apparent

Step 2: Identifying relevant work

The search for studies should be extensive. Multiple resources (both computerized and printed) should be searched without language restrictions. The study selection criteria should flow directly from the review questions and be specified a priori. Reasons for inclusion and exclusion should be recorded

Step 3: Assessing the quality of studies

Study quality assessment is relevant to every step of a review. Question formulation (Step 1) and study selection criteria (Step 2) should describe the minimum acceptable level of design. Selected studies should be subjected to a more refined quality assessment by use of general critical appraisal guides and design-based quality checklists (Step 3). These detailed quality assessments will be used for exploring heterogeneity and informing decisions regarding suitability of meta-analysis (Step 4). In addition they help in assessing the strength of inferences and making recommendations for future research (Step 5)

\section{Step 4: Summarizing the evidence}

Data synthesis consists of tabulation of study characteristics. quality and effects as well as use of statistical methods for exploring differences between studies and combining their effects (meta-analysis). Exploration of heterogeneity and its sources should be planned in advance (Step 3). If an overall meta-analysis cannot be done, subgroup meta-analysis may be feasible

\section{Step 5: Interpreting the findings}

The issues highilighted in each of the four steps above should be met. The risk of publication bias and related biases should be explored. Exploration for heterogeneity should help determine whether the overall summary can be trusted, and, if not, the effects observed in high-quality studies should be used for generating inferences. Any recommendations should be graded by reference to the strengths and weaknesses of the evidence

Figure 1: Five Steps in Systematic Review

Source: Five Steps to Conducting a Systematic Review (Journal of the Royal Society of Medicine, Vol 96, 2003) 


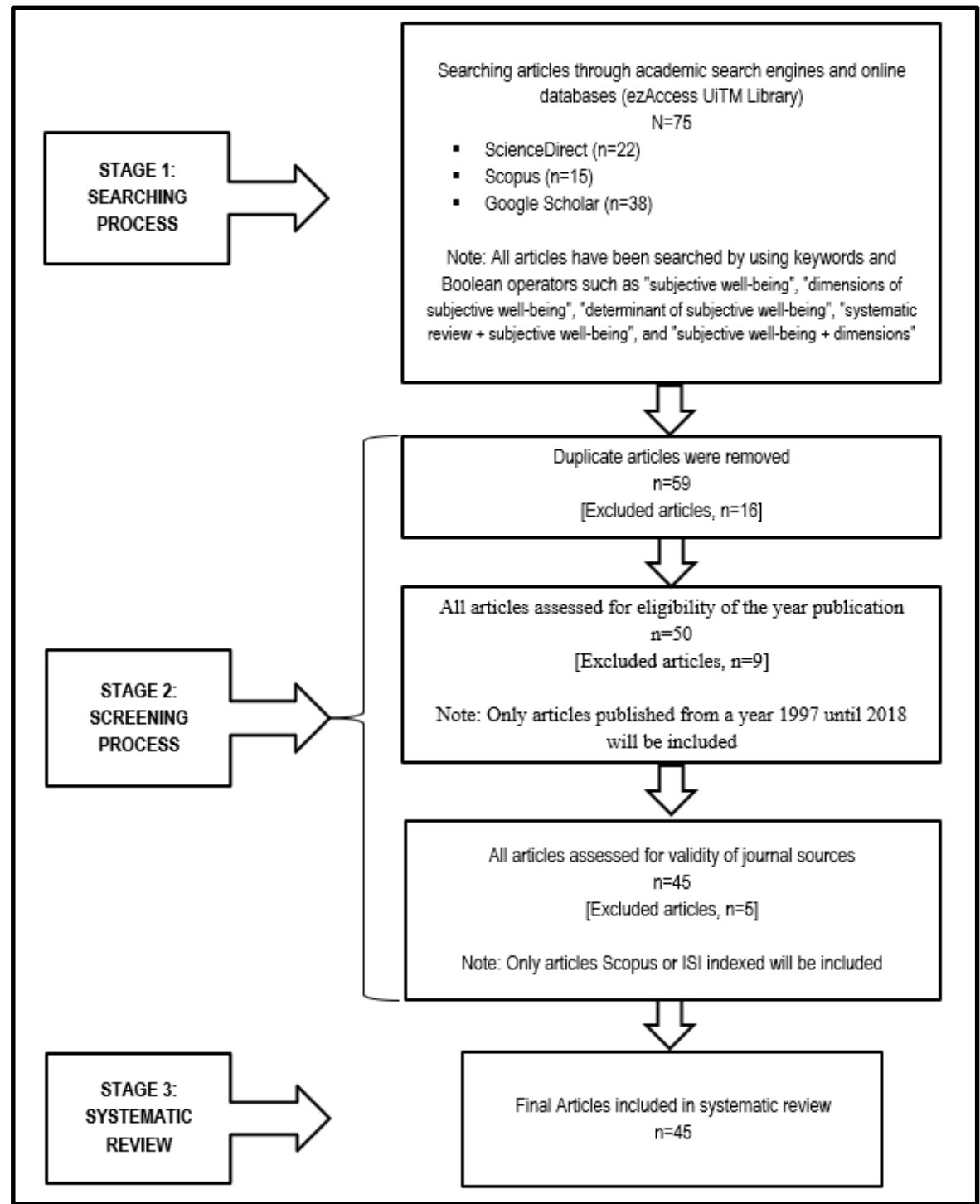

Figure 2: Flow Diagram of Searching Related Articles

Khan, Kunz, Kleijnen, and Antes (2003) has been used as guidance for the purpose of this current review (Figure 1). In reviewing the articles, there are three main stages followed in this study that comprises Searching Process, Screening Process and Systematic Review Process. Detail of the process is shown in Figure 2. The present review was carried out 
between September 2017 and Mac 2018. In overall, 75 articles have been extracted from academic search engines and online databases (ezAccess UiTM Library) such as ScienceDirect, Scopus and also through Google Scholar. All the articles in have been retrieved by using several related keywords and Boolean operators. These include "subjective well-being", "dimensions of subjective well-being", "determinant of subjective well-being", "systematic review + subjective well-being", and "subjective well-being + dimensions" as a search strategy. Next, a screening process was conducted to examine the eligibility of the articles to be included in this review. Only articles have been published from the year 1997 until 2018 from related journals indexed in Scopus and ISI and will be reviewed. Scimago online system has been used to examine the validity of the journal sources for the articles obtained from Google Scholar. The following are four inclusion criteria to carry out this review:

(1) The sources of the articles had been extracted.

(2) Keywords and Boolean operators used to retrieve the article.

(3) Year of publication.

(4) Scopus and ISI indexed journals.

All the articles which not met one of these inclusion criteria were being excluded. Detail number of articles obtained from the Google Scholar, ScienceDirect and the Scopus are shown in Figure 2. After their eligibility has been confirmed, from a total, only 45 articles.

\subsection{Findings and Discussion}

\subsection{Measurement Instrument of the Subjective Well-Being}

Several instruments are available in measuring SWB of the respondents. These instruments have been used in a wide range of studies which generally focusing on happiness and life satisfaction. Among the most frequently used measurement instruments in SWB survey are Satisfaction with Life Scale and General Happiness questionnaire using a Likert rating scale format as a response alternative. The Satisfaction With Life Scale (SWLS) was designed by Diener, Emmons, Larsen and Griffin (1985). By using only five items with 7-point scale (1= strongly disagree, 2 = disagree, 3 = slightly disagree, $4=$ neither agree nor disagree, $5=$ slightly agree, 6 = agree, 7 = strongly agree.), this measurement instrument was developed to measure the concept of life satisfaction based on overall judgement of respondents' life. In contrast, a study conducted by Kobau, Sniezek, Zack, Lucas and Burns (2010) had used only 5-point Likert scale ( $1=$ strongly disagree, 2 = disagree, 3 = neither agree nor disagree, $4=$ agree, $5=$ strongly agree.), to measure satisfaction with life of respondents. In addition, Lyubomirsky and Lepper (1999) developed the General Happiness Scale with four items and a 7-point scale. The respondents were asked to indicate their response to each item with an appropriate number in the end-anchored scale ranges from 1 to 7 .

From another source of literature, the life satisfaction and happiness have also been measured separately in several related domains such as satisfaction towards job, income, health, financial etc. The questions related to the life satisfaction has also been constructed in the form of "How satisfied are you ...." as the following examples: "In general, how satisfied 
are you with your life?" (Power \& Kuyken, 1998), "How satisfied are you with your sleep?" (Kuyken, 1995), "How satisfied are you with your job as a whole, everything is taken into consideration" (Nielsen, Yarker, Randall, \& Munir, 2009), "How satisfied are you with your current overall pay level?" (Greenberg, 1990) and "How satisfied are you with your economic conditions?" (Clark, Kristensen, \& Westergård-Nielsen, 2009). While for the happiness, some of the previous researchers have formulated their questions as "How would you rate your happiness at the moment? (Andrew, 2009), "How would you rate your own general happiness?" (Uchida \& Oishi, 2016) and "How would you rate your current level of happiness?" (Yamamura et al., 2015).

\subsection{Contributing Factors of Subjective Well-Being}

There are several factors contribute significantly to the SWB of the individual. From the literature, it is found that the personality traits, socioeconomic status, health condition, religious commitment and spirituality are among the factors may influence the SWB of the respondents. These will be discussed in the subsequent subtopics.

\subsubsection{Personality Traits}

Most of the previous studies examine the influence of the personality factors on SWB of the respondents. These include the effect of personality traits (e.g., Openness, Conscientiousness, Extraversion, Agreeableness, and Neuroticism) on life satisfaction, happiness, positive affect and negative affect (Chan \& Joseph, 2000; Diener, Oishi, \& Lucas, 2003; Diener \& Lucas, 1999; Dolan, Peasgood, \& White, 2008; Gutierrez, Jimenez, Hernandez, \& Pcn, 2005; Hayes \& Joseph, 2003; Lucas \& Diener, 2008; Schimmack, Radhakrishna, Oishi, Dzokoto, \& Ahadi, 2002; Steel, Schmidt, \& Shultz, 2008). As Lucas and Diener (2008) pointed out that, there is a strong relationship between personality and SWB. A meta-analysis conducted by DeNeve, Kristina, and Cooper (1998) revealed that among Big Five personality factors (e.g., Openness, Conscientiousness, Extraversion, Agreeableness, and Neuroticism), Neuroticism was strongly affecting the life satisfaction, happiness and negative affect, while Extraversion and Agreeableness was significantly influenced the positive affect. They also found that, the personality traits are equally predictive of life satisfaction, happiness and positive affect, but less predictive of negative effect. It is found that besides the personality traits such as Neuroticism and Extraversion, self-esteem also significantly influence the levels of SWB (Diener et al., 2003). A study by Hayes and Joseph (2003) shown that life satisfaction can be predicted well by Neuroticism and Conscientiousness, and happiness was affected by Extraversion and Neuroticism.

Likewise, as pointed out by Gutierrez et al., (2005), the Extraversion and Neuroticism are the most important factors that influence the SWB of the individual. Moreover, the result from this study also revealed that the Openness has contributed significantly to the positive and negative affect. Another study by Chico Libran (2006) also claimed that Extraversion and Neuroticism were explained $52 \%$ of the total variance in a regression model. Aziz, Mustaffa, Samah, and Yusof (2014) carried out a survey to examine the relationship between personality and happiness among 317 academicians in Malaysia. The results showed that the happiness of the lecturers has been positively influenced by Extraversion, 
Agreeableness, Conscientiousness and Openness. However, the Neuroticism has negatively affected the happiness of the lecturers involved in the study. Similarly, the findings from Malkoc (2011) also found that SWB was negatively influenced by Neuroticism, whereas SWB was positively affected by Extraversion and Conscientiousness. To sum up, although there is a link between personality traits and the level of SWB, however, the results might be influenced by the study context focused by researchers. This is because, from the review, it is shown that different context of studies will reveal different findings. This includes the direction of the relationship (either negatively influence or positively influence). It is found that lack of study attempts to see whether respondent demographics such as gender, race, education level and etc., may affect the influence of personality traits on SWB. Therefore, in the future study, it is more valuable to extend the research by examining the effect of demographics as a mediator on the influence of personality traits on SWB of the respondents.

\subsubsection{Socioeconomic Status}

Besides that, socioeconomic status (e.g., Income, financial condition, etc.) is also found to be significantly affecting SWBs. A result from a meta-analysis by Pinquart and Sorensen (2000) has shown that there is a relationship between income and SWB. Although income is not a sole predictor of life satisfaction and happiness of individuals, Cummins (2000) found that money not only influences life satisfaction but also can buys happiness. In addition, according to Lucas and Diener (2008), income and wealth have significantly affect SWBs. Life satisfaction is strongly influenced by the high level of income earned by the respondents, as low income will cause low life evaluation and low emotional well-being (Kahneman \& Deaton, 2010). The current happiness of the people in rural China also has influenced by the relative income they earned (Knight, Lina, \& Gunatilaka, 2009). Hochman and Skopek (2013) also showed that by controlling for income, wealth has an impact on general life satisfaction, with the poor reporting less satisfaction in life. $\mathrm{Ng}$ and Diener ( 2018) also reported that, as compared to those who earned lower incomes, higher income people will have higher life evaluation and positive feelings and lower negative feelings. Apart of income, Chan and Joseph (2000) also revealed that financial success significantly contributed to the higher level of happiness. Moreover, financial commitment such as debt was found to slightly decrease respondents' general life satisfaction (Hochman \& Skopek, 2013).

It is also believed that there is an indirect relationship between the employment status and SWB, as it will affect both income and financial condition of the person. Past study reported that as comparing to those who are employed, an unemployed person has shown a low level of SWBs (Tomas, 1997). The two consecutive survey conducted by Winkelmann (2009) which examined the level of SWB with reference sample consists of individuals who made a transition from employment to unemployment shown that on average the level of SWB significantly dropped both for men and women when being unemployed rather than employed. As compared to the women, the level of SWB is found to be the lowest for unemployed men(Stam, Sieben, Verbakel, \& de Graaf, 2016). The findings from this study also shown that employed men and women have the highest SWBs, followed by retired, unemployed and non-working disabled. From the Korea Labour and Income Panel Survey (2001, 2003-2007), revealed that the level of SWB of a wife with an unemployed husband 
was significantly low (Kim \& Do, 2013). As an unemployment becoming a serious issue and cause of living is drastically rising nowadays, hence it is important to further research on the association of employment-income-financial and their implication on SWB of the people because it will give a clear picture on what people being experienced in current life.

\subsubsection{Health Condition}

Health status is one of the contributing factors to SWB. Usually, people who are suffered by a certain disease will be less satisfied and less happy with their life. Previous studies have shown that the relationship between health and SWB of an individual is positively significant. Many of studies have revealed that better health condition has lead to higher level of life satisfaction (Gwozdz \& Sousa-Poza, 2010; Melin, Fugl-Meyer, \& Fugl-Meyer, 2003) and also the happiness of the people. Xu and Roberts (2010) also remarked that the SWB can be predicted well by health. As pointed out by Dolan, Peasgood, and White (2008), apart from separation, unemployment and lack of social contact, poor health strong negatively associated with SWB. It is shown that less healthy people will have low SWBs. Physical health is directly related to the SWBs, which also mediately linked to the age of the individual (Steptoe, Deaton, \& Stoone, 2015). Steptoe et al., (2015) found that older people with an illness such as coronary heart disease, arthritis and chronic lung show both increased levels of depressed mood and impaired hedonic and eudaimonic well-being.

One's health not only can influence the SWB of the people, but the previous study also showed that life satisfaction and happiness could also give an effect to the condition of health of an individual. Diener and Chan (2011) in their analysis found that SWB such as life satisfaction, an absence of negative emotions, optimism and positive emotion leads to better health and longevity. In contrast, according to Miquelon and Vallerand (2006), happiness does not provide any benefits to the physical health. Ngamaba, Panagioti and Armitage (2017) have claimed that to improve the SWB of the citizens in the country, it is important for the government to focus on the measures that need to be taken to improve the health of the people in their country. As health and SWB were interconnected to each other, therefore it is worth to pursue a study to examine both the influence of health on SWB and the influence of SWB on health simultaneously, where it will provide useful findings for better action to be taken by the policymakers.

\section{3..2.4 Religious Commitment and Spirituality}

Fabricatore, Handal and Fenzel (2000) suggested that when facing a stress, spirituality will assist the people to maintain their life satisfaction. Another study by Kausar and Haroon (2004) found that religious affiliation is also one of the best predictors of SWB among Eastern Muslim culture besides of work satisfaction, social support, social class, income level and marital status. As stated by Neal (2003), older adults who derive a sense of meaning in life from religion activities will have a higher level of life satisfaction. Besides that, Lucas and Diener (2008) also highlight that apart of income and wealth, SWB of the people were significantly influenced by religious commitment influence. Since it is shown that the religious commitment and spirituality are another are factors that can assist people to feel good about their life. As previous studies have shown that the religious commitment and spirituality were 
significantly affecting SWBs, therefore to gain more insight, future researchers may consider examining whether these factors could also mediate the effects of socioeconomic status, personality traits and health on the SWB in the future research.

\subsection{Conclusion}

In conclusion, it appears that several factors such as personality traits, socioeconomic status, health condition, religious commitment and spirituality were contributed significantly to the SWB of the people. Although a different context of study will reveal different findings, the results obtained still provide significant input to proceed with a future research. It is also found that the socio-demographic status of respondents might affect the results obtained, required further attention by the researchers.

\subsection{Recommendation}

To gain more insight on the factors contributed to the SWB of the people, it is suggested that for future researchers to review related articles from other search engines and online databases that published before the year 1997. Future researchers also need to conduct an interview with a target group of respondents in order to obtain a deeper understanding and more relevant information from respondents based on what they being experienced. Before the actual survey wants to be carried out, it is required for the researchers to validate the measurement instrument used. It is to ensure that the instrument fulfils the psychometric properties including both validity and reliability. Empirical research with the target group of respondents should be taken as the findings obtained will produce more accurate findings which can assist related bodies or agencies in making more practical and inform decision. As the socio-demographic status of respondents is found to affect the findings, it is also more practical to make a comparison of SWB across the related group of respondents (e.g., gender, age, race etc.). In order to gain more insight, the survey should be conducted to a wide range of the sample, so that researchers can assess the possible trend occur. This will serve the policymakers in making good policies which benefit all the citizens in the country. The findings from the survey on SWB may be used as an input for the government in implementing more holistic and effective public policies which benefits society in overall.

\section{References}

Andrew, J. (2009). Happiness and Productivity. Journal of Labor Economics, 33(4), 789-822.

Aziz, R., Mustaffa, S., Samah, N. A., \& Yusof, R. (2014). Personality and Happiness among Academicians in Malaysia. Procedia - Social and Behavioral Sciences, 116(1995), 4209-4212.

Brunstein, J. C. (1993). Personal goals and subjective well-being: A longitudinal study. Journal of Personality and Social Psychology, 65(5), 1061. 
Chan, R., \& Joseph, S. (2000). Dimensions of personality, domains of aspiration, and subjective well-being. Personality and Individual Differences, 28(2), 347-354.

Chico Libran, E. (2006). Personality dimensions and subjective well-being. The Spanish Journal of Psychology, 9(1), 38-44.

Clark, A. E., Kristensen, N., \& Westergård-Nielsen, N. (2009). Economic satisfaction and income rank in small neighbourhoods. Journal of the European Economic Association, 7(2-3), 519-527.

Cummins, R. A. (2000). Personal income and subjective well-being: A review. Journal of Happiness Studies, 1(2), 133-158.

DeNeve, Kristina, M., \& Cooper, H. (1998). The happy personality:A meta-analysis of 137 personality traits and subjective well-being. Psychological Bulletin, 124(2), 197-229.

Diener, E. (1984). Subjective well-being. Psychological Bulletin.

Diener, E., \& Chan, M. Y. (2011). Happy People Live Longer: Subjective Well-Being Contributes to Health and Longevity. Applied Psychology:Health and Well-Being, 3(1).

Diener, E., Diener, M., \& Diener, C. (1995). Factors predicting the subjective well-being of nations. Journal of Personality and Social Psychology, 69(5), 851-864.

Diener, E., Emmons, R. A., Larsen, R. J., \& Griffin, S. (1985). The Satisfaction With Life Scale. Journal of Personality Assessment, 49(1), 71-5.

Diener, E., \& Lucas, R. E. (1999). 11 personality and subjective well-being. In Well-being: Foundations of Hedonic Psychology (p. 213).

Diener, E., Oishi, S., \& Lucas, R. (2012). Subjective Well-Being: The Science of Happiness and Life Satisfaction

(2nd ed.). The Oxford Handbook of Positive Psychology:Oxford University Press.

Diener, E., Oishi, S., \& Lucas, R. E. (2003). Personality, culture, and subjective well-being: Emotional and cognitive evaluations of life. Annual Review of Psychology, 54(1), 403-425.

Diener, E., Oishi, S., \& Lucas, R. E. (2015). National accounts of subjective well-being. American Psychologist, 70(3), 234-242.

Diener, E., \& Suh, E. (1997). Measuring quality of life: economic, social, and subjective indicators. Social Indicators Research, 40(1/2), 189-216.

Diener, E., Suh, E., \& Oishi, S. (1997). Recent findings on subjective well-being. Indian Journal of Clinical Psychology.

Dolan, P., Peasgood, T., \& White, M. (2008). Do we really know what makes us happy? A review of the economic literature on the factors associated with subjective well-being. Journal of Economic Psychology, 29(1), 94-122.

Fabricatore, A. N., Handal, P. J., \& Fenzel, L. M. (2000). Personal spirituality as a moderator of the relationship between stressors and subjective well-being. Journal of Psychology and Theology, 28(3), 221.

Greenberg, J. (1990). Employee theft as a response to underemployment inequity: the hidden costs of pay cuts. Journal of Applied Psychology, 75(5), 561-568. 
Gutierrez, J. L. G., Jimenez, B. M., Hernandez, E. G., \& Pcn, C. (2005). Personality and subjective well-being: Big five correlates and demographic variables. Personality and Individual Differences, 38(7), 1561-1569.

Gwozdz, W., \& Sousa-Poza, A. (2010). Ageing, health and life satisfaction of the oldest old: An analysis for Germany. Social Indicators Research, 97(3), 397-417.

Hayes, N., \& Joseph, S. (2003). Big 5 correlates of three measures of subjective well-being. Personality and Individual Differences, 34(4), 723-727.

Hochman, O., \& Skopek, N. (2013). The impact of wealth on subjective well-being: A comparison of three welfarestate regimes. Research in Social Stratification and Mobility, 34, 127-141.

Kahneman, D., \& Deaton, A. (2010). High income improves evaluation of life but not emotional well-being. Proceedings of the National Academy of Sciences of the United States of America, 107(38), 16489-16493.

Kausar, S., \& Haroon, R. C. (2004). Predictors of Subjective Well-Being in an Eastern Muslim Culture. Journal of Social and Clinical Psychology, 23(3), 359-376.

Khan, K. S., Kunz, R., Kleijnen, J., \& Antes, G. (2003). Five steps to conducting a systematic review. Journal of the Royal Society of Medicine, 96(3), 118-121.

Kim, M. H., \& Do, Y. K. (2013). Effect of husbands' employment status on their wives' subjective well-being in Korea. Journal of Marriage and Family.

Knight, J., Lina, S. O. N. G., \& Gunatilaka, R. (2009). Great expectations? The subjective well-being of rural-urban migrants in China. China Economic Review, 20(4), 635-649.

Kobau, R., Sniezek, J., Zack, M. M., Lucas, R. E., \& Burns, A. (2010). Well-being assessment: An evaluation of well-being scales for public health and population estimates of well-being among US adults. Applied Psychology: Health and Well-Being, 2(3), 272-297.

Kuyken, W. (1995). The World Health Organization quality of life assessment (WHOQOL): position paper from the World Health Organization. Social Science and Medicine, 41(10), 1403-1409.

Lucas, R. E., \& Diener, E. (2008). Subjective well-being. In Handbook of Emotions (pp. 471-484).

Lyubomirsky, S., \& Lepper, H. S. (1999). A measure of subjective happiness: preliminary reliability and construct validation. Social Indicators Research, 46(2), 137-155.

Malkoc, A. (2011). Big five personality traits and coping styles predict subjective wellbeing: A study with a Turkish sample. Procedia - Social and Behavioral Sciences, 12, 577-581.

Melin, R., Fugl-Meyer, K. S., \& Fugl-Meyer, A. R. (2003). Life satisfaction in 18-to 64-year-old Swedes: in relation to education, employment situation, health and physical activity. Journal of Rehabilitation Medicine, 35(2), 84-90.

Miquelon, P., \& Vallerand, R. J. (2006). Goal motives, well-being, and physical health: Happiness and self-realization as psychological resources under challenge. Motivation and Emotion, 30(4), 259-272.

Neal, K. (2003). Religious Meaning and Subjective Well-Being in Late Life. Journals of Gerontology - Series B Psychological Sciences and Social Sciences, 58(3), 160-170.

Ng, W., \& Diener, E. (2018). Affluence and Subjective Well-Being: Does Income Inequality Moderate their Associations? Applied Research in Quality of Life, 1-16. 
Ngamaba, K. H., Panagioti, M., \& Armitage, C. J. (2017). How strongly related are health status and subjective wellbeing? Systematic review and meta-analysis. European Journal of Public Health, 27(5), 879-885.

Nielsen, K., Yarker, J., Randall, R., \& Munir, F. (2009). The mediating effects of team and self-efficacy on the relationship between transformational leadership, and job satisfaction and psychological well-being in healthcare professionals: A cross-sectional questionnaire survey. International Journal of Nursing Studies, 46(9), 1236-1244.

Pinquart, M., \& Sorensen, S. (2000). Influences of socioeconomic status, social network, and competence on subjective well-being in later life: A meta-analysis. Psychological and Aging, 15(2), 187-224.

Power, M., \& Kuyken, W. (1998). the World Health Organization Quality of Life Assessment (Whoqol): Development and General Psychometric Properties* the Whoqol Group\{. Social Science and Medicine, 46(12), 1569-1585.

Schimmack, U., Radhakrishna, P., Oishi, S., Dzokoto, V., \& Ahadi, S. (2002). Culture, personality, and subjective well-being: integrating process models of life satisfaction. Journal of Personality and Social Psychology, 82(4), 582.

Stam, K., Sieben, I., Verbakel, E., \& de Graaf, P. M. (2016). Employment status and subjective well-being: the role of the social norm to work. Work, Employment and Society, 30(2), 309-333.

Steel, P., Schmidt, J., \& Shultz, J. (2008). Refining the relationship between personality and subjective well-being. Psychological Bulletin, 134(1), 138.

Steptoe, A., Deaton, A., \& Stoone, A. A. (2015). Subjective wellbeing, health, and ageing. The Lancet, 385(9968), 640-648.

Tomas, K. (1997). Is utility related to employment status? Employment, unemployment, labor market policies and subjective well-being among Swedish youth. Labour Economics, 4(2), 125-147.

Uchida, Y., \& Oishi, S. (2016). The Happiness of Individuals and the Collective. Japanese Psychological Research, 58(1), 125-141.

Winkelmann, R. (2009). Unemployment, social capital, and subjective well-being. Journal of Happiness Studies, 10(4), 421-430.

Xu, J., \& Roberts, R. E. (2010). The power of positive emotions: It's a matter of life or death-Subjective well-being and longevity over 28 years in a general population. Health Psychology, 29(1), 9-19.

Yamamura, E., Tsutsui, Y., Yamane, C., Yamane, S., Powdthavee Cep, N., \& Powdthavee Miaesr, N. (2015).

Trust and Happiness: Comparative Study Before and After the Great East Japan Earthquake. Social Indicators Research, 123, 919-935. 